\title{
Empirical Study of the Relation between Open Source Software Use and Productivity of Japan's Information Service Industries
}

\author{
Keisuke Tanihana and Tetsuo Noda \\ Shimane University \\ \{keisuke_tanihana, nodat\} @soc.shimane-u.ac.jp
}

\begin{abstract}
This paper analyzes the relation between OSS (Open Source Software) use and the performance of Japanese information service industry. We first estimate the market value of OSS, an issue which only a few studies have specifically addressed. The results are then used to analyze the economic effect of OSS. Although our study has some methodological limitations regarding the calculation of the market value of OSS, we demonstrate that the economic effect of OSS is generally positive.
\end{abstract}

\section{Introduction}

This paper examines the relation between the use of Open Source Software (OSS) and the productivity of the Japanese information service industry from an economic perspective. OSS has recently become an indispensable resource in the information service industry. As Raymond (1998) has shown, the spread of open software development is associated with the increasing participation and contribution of information service enterprises. These enterprises use OSS primarily to enhance their competitive advantage. The open source community continually updates the software on a voluntary basis and, although this input is quite independent of enterprise needs, information service enterprises are the beneficiaries of this process. Chesbrough (2003) accurately described this as "open innovation" process to denote not only the enrichment of an enterprise's "inner" resources, but also the increasing importance of using "outer" resources such as OSS, especially when enterprises regard their competitiveness and growth in productivity as indispensable.

We adopt the view of OSS as an "outer" resource to analyze the business model in the Japanese information service industry in terms of its productivity.

\section{Research Design}

Tanihana and Noda (2011) used the concept of "open innovation" to study the relation between software development style and the use of OSS by showing the connections between "inner" and "exterior" resources. This section of our paper is devoted to explaining the theoretical background of OSS. 


\subsection{The Concept of "Connection"}

Although the cost of duplicating software is almost negligible, the results of OSS development are made freely available. Therefore, unless there is a scarcity of talented developers, OSS may be regarded as a kind of public good that is non-competitive and non-exclusive. In the view of Ghosh (1998), all enterprises $\mathrm{i}(\mathrm{i}=1,2, \mathrm{n})$ can use OSS because of these two attributes. This relation is defined by formula (1):

$$
\operatorname{OSS}_{1}=\mathrm{OSS}_{2}=\ldots=\mathrm{OSS}_{n}
$$

Ghosh (1998) highlighted the ease of duplicating software. In our view, the open style business model accompanying information oriented economy and copyright strengthen his opinion about OSS. We will examine the concept of "open" from the perspective of changes to an enterprise's business style ${ }^{1}$.

The use of OSS reduces an enterprise's transaction costs, as defined by Coase (1937), and changes its economic structure and business model from economy of scale to economy of "connection," as noted by Miyazawa (1986a, 1986b, 1988). Economy of "connection" is a concept that is not applicable to a single enterprise, but rather the synergy effect produced by many enterprises sharing their technological expertise.

On the other hand, Raymond (1998) used the expression "cathedral and bazaar," to distinguish between software development styles, likening the OSS development style, which is open to any other developer, as a bazaar style. In this style, OSS developers are "connected" through the Internet, thereby producing value ${ }^{2}$. On this point, it is thought that the development of OSS beyond the "inner" organization indicates the existence of an economy of "connection."

\subsection{Open Innovation and OSS Utilization}

In considering the development of OSS, the connection of "inner" resources with "outer" resources is a vital point. In our view, the development of OSS and its business model is based on the concept of "open innovation" advocated by Chesbrough (2003).

To strengthen their competitive advantage, enterprises generally keep the results of their R\&D activities secret, an attitude which Kokuryo (1995) argues may be characterized as a manifestation of independent management. However, under an "open innovation" process, an enterprise's R\&D activities are connected to "outer" resources, thereby creating new value. In other words, changes to a business model occur from the reductions in transaction costs, as defined by Coase (1937), with the with the economy of "connection" serving as a driving force for "open innovation." In considering the development of OSS, the connection of "inner" resources with

1 Regarding changing business styles in enterprises, Kokuryo (1995) points out the change in the form of information processing from centralized to distributed processing.

2 Raymond's (1988) statement that "Given enough eyeballs, all bags are shallow." is another interesting way of expressing the "connect" effect. 


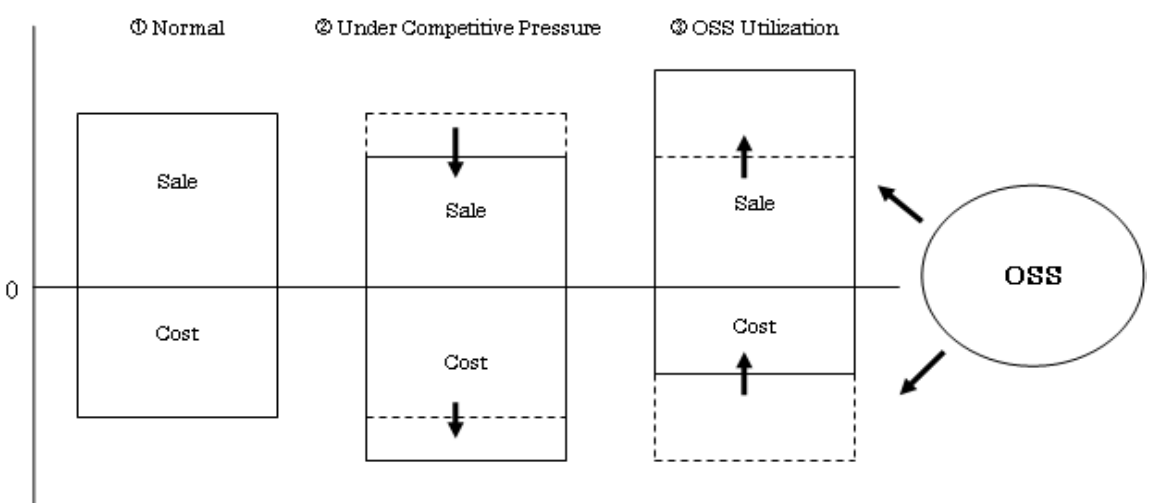

Fig. 1. Structure of Sale, Cost and OSS in Information Service Enterprise

"outer" resources is a vital point. In our view, the development of OSS and its business model is based on the concept of "open innovation" advocated by Chesbrough (2003).

To strengthen their competitive advantage, enterprises generally keep the results of their R\&D activities secret, an attitude which Kokuryo (1995) argues may be characterized as a manifestation of independent management. However, under an "open innovation" process, an enterprise's R\&D activities are connected to "outer" resources, thereby creating new value. In other words, changes to a business model occur from the reductions in transaction costs, as defined by Coase (1937), with the economy of "connection" serving as a driving force for "open innovation."

The Linux Foundation (2010) has shown that approximately $70 \%$ of contributions to OSS are by business enterprises, and that OSS activities are included in profit growth activities. Thus, enterprises use OSS to enhance their competitiveness. Kunai (2010) points out that revenue is generated from a contribution to the OSS community, whereas Fukuyasu (2011) considers the leveraging effect of using OSS. In the latter's view, the cost of developing OSS is shared among contributors, and all market players can enjoy the results produced by the contributors. Consequently, the positive economic effect of OSS takes the form of cost reductions and increased profits because of the leveraging effect of R\&D activities.

Thus, for business models that use OSS, the vital point is that value, which cannot be created through independent management, is produced through the "connection" between "inner" and "outer" resources. In addition, OSS is a standard technology produced by the community independently of the enterprises contributing to it. Thus, it is a kind of infrastructure characterized by non-competition and non-exclusion.

We shall consider the business model that uses OSS from the perspective of value addition. Figure 1 shows the relation between sales and costs in information service enterprises. We define the difference between the sale of products or services and development or management costs as value added to an information service enterprise. It is well established that a fundamental objective of all enterprises is to maximize their value added activities. 
However, as the center of Figure 1 shows, competitive pressure on services and products is a daily and commonplace necessity. Because each enterprise has to deal with this pressure, price competition will be unavoidable. As a result, there is a fall in sales. On the other hand, under competitive pressure, it is necessary for each enterprise to produce more attractive products and services with a greater market appeal than before. This triggers a rise in development costs. That is, under competitive pressure, because its sales fall and its costs rise, each enterprise will face a reduction in its added value.

The context in which OSS is used is shown on the left side of Figure 1. Because OSS is generally made freely available, enterprises are able to reduce development costs by replacing internal resources with external resources, or by "connecting" both. Similarly, it will be possible for each enterprise to generate profits and surpass its rivals in technology and competitive advantage by "connecting" its own products or services with OSS-based technology, which is developed out-side the enterprise. This process appears to facilitate competitive pricing by enterprises.

As already mentioned, our hypothesis is that using OSS can potentially enhance an information service enterprise's capacity to create added value. Therefore, we attempt to grasp the structural and quantitative effects of OSS in this paper.

\subsection{Model for Empirical Analysis}

To analyze the economic effects of OSS, we have to consider the effect of "connection" with respect to resources. If the "connection" between "inner" resources and OSS as "outer" resource is considered, an information service enterprise $i$ 's production structure can be expressed by formula (2), as follows:

$$
V_{i, t}=A K_{i, t}^{\alpha} L_{i, t}^{(1-\alpha)} O S S_{t}^{\gamma}
$$

Formula (2) is a kind of Cobb-Douglas production function ${ }^{3}$, according to which, given technology $\mathrm{A}$, value in an information service enterprise $i V_{i, t}$ consists of its capital input $\mathrm{K}_{i, t}$ and labor input $\mathrm{L}_{i, t}$. These resources exist in the "inner" organization. On the other hand, $O S S_{t}$ constitutes the "outer" resources, which develop independently of each enterprise $i$. In other words, the relation indicated in formula (2) shows the "connection" between "inner" resources and "outer" resources that lies behind the "open innovation" business model".

If formula (2) is logarithm-zed and deployed, it is possible to obtain formula (3), which specifies the determinants of labor productivity in an information service enterprise.

$$
\ln \left(\frac{V}{L}\right)_{i, t}=\ln A+\alpha \ln \left(\frac{K}{L}\right)_{i, t}+\gamma \ln O S S_{t}
$$

This production function is a fundamental technique in economic growth factor analysis.

4 This relationship revealed by formula (2) is based on public goods economic analysis model, which is studied by Ashauer (1989) and Ford and Porter (1991). 
In formula (3), the level of labor productivity $(V / L)$ depends on the level of ratio of capital equipment $(K / L)$ and OSS input. In this formula, the value of coefficient $\gamma$ is important. When $\gamma$ is positive and significant statistically, OSS gives positive effect to the level of labor productivity in Japan's information service industry.

\section{Data Resources and OSS Market Value}

\subsection{Data Resources}

$\underline{V}_{i, t}:$ Value added in information service enterprises

For the data on value added, we used "Currently Survey of Selected Service Industries" released by Japan's Ministry of Economy, Trade and Industry.

$<$ http://www.meti.go.jp/statistics/tyo/tokusabido/index.html>

$\underline{K}_{i, t}:$ Capital input in information service enterprises

For the above, we used data from the "Currently Survey of Selected Service Industries" released by Japan's Ministry of Economy, Trade and Industry.

$<$ http://www.meti.go.jp/statistics/tyo/tokusabido/index.html>

\section{$\underline{L}_{i, t}:$ Labor input in information service enterprises}

Labor input is composed of the number of workers and the number of labor hours in this paper. For data on the number of workers, we used the "Currently Survey of Selected Service Industries" released by Japan's Ministry of Economy, Trade and Industry. We obtained the labor hours data from the "Monthly Labor Survey Statistics" released by Japan's Ministry of Health, Labor and Welfare.

<http://www.mhlw.go.jp/toukei_hakusho/toukei/>

\section{$\underline{w}_{t}:$ Wages for programmer}

We used the "Basic Survey on Wage Structure" published by Japan's Ministry of Health, Labor and Welfare for the data on the wages for programmers.

<http://www.mhlw.go.jp/toukei_hakusho/toukei/>

\subsection{Calculation of OSS Market Value}

Although software is an intangible asset, quantitative evaluations, such as price, are required to determine the economic effect of OSS. In software development, the person-month scale is generally applied. On the other hand, the value of software is evaluated in terms of market transactions. In our view, the difference between the standards of the person-month scale and the market price makes it difficult to evaluate the economic effect of OSS.

Moreover, there are no official statistics, such as price and market value, for OSS. Although OSS increasingly resembles economic activity in recent years, it was not necessarily developed to obtain evaluation and market share data at the outset. This is one reason why it does not lend itself easily to quantitative assessments in relation to 
measurements such as price and market value. Therefore, to evaluate the market value of OSS, it is necessary to change from an obscure standard such as person-month to something more obvious, such as price.

Other scholars have undertaken a few quantitative assessments of OSS. MacPherson et al. (2008) calculated the development cost of Fedora9, and estimated it at 10.8 billion dollars. Glott and Haaland (2009) also evaluated the development cost of Debian as approximately 12 billion euros. Furthermore, Garcia-Garcia and Magdaleno (2010) estimate the market value of the Linux kernel (version 2.6.30) at 1 billion euros. For their monetary assessments of OSS, MacPherson et al. (2008) and Garcia-Garcia and Magdaleno (2010) used a Constructive Cost Model (COCOMO), which calculates a process and a period for software development ${ }^{5}$. COCOMO is a method that is advocated in Boehm (1981) and it can estimate the effort that goes into software development on a person-month scale, based on a line of source code. Multiplying such effort estimates by wages makes it possible to evaluate the monetary value of OSS. We shall use the same method to estimate the market value of OSS in this paper. For this purpose, we shall use the following formula.

$$
E F F O R T_{t}=a\left(K S L O C_{t}\right)^{b} \prod_{j=1}^{m} C_{j}
$$

Formula (4) is a basic COCOMO, in which the man-month scale effort $E F F O R T_{t}$ depends on the kilo source line of code $K S L O C_{t}$ and cost factors $C_{j}$. Coefficients $a$ and $b$ are the parameters which are determined by the scale and the environments in software development; these are computed by regressing past development projects as reported in Boehm (1981). Based on MacPherson (2008), we set coefficient $a$ at 2.4 and $b$ at $1.05^{6}$. For the number of lines of source code, we adopt statistics released by Ohloh, which is a project that publishes statistics and information about $\mathrm{OSS}^{7,8}$.

In COCOMO, cost factors are composed of 15 variables, including hardware, human resources, and project environments. A coefficient was assigned to each of these factors. Then, based on Wheeler (2004), we assigned to the development of OSS a cost factor parameter of 2.4. Wheeler (2004) has demonstrated that software development not only requires a labor force, but also the capacity to meet the costs of tests, facilities, and management. Because the proportion of labor force input is one of the cost factors in software development, it is necessary to count the variable multiplied by a cost factor coefficient of 2.4 as a development cost.

5 The development effort calculated by basic COCOMO does not depend on the kind of programming languages, but rather the number of lines of source code. On this point, it seems that COCOMO maintains the objectivity of calculation. However, it is necessary to realize that this technique does not take into consideration the programming language.

6 There can be three levels to a software development project in COCOMO: Organic, Semidetached, and Embeded. That is, each parameter is set as $a=2.4, b=1.05$ at Organic, $a=3.0$, $b=1.12$ at Semi-detached, and $a=3.6, b=1.20$ at Embedded.

7 Ohloh is a project which supplies information about OSS development, publishing about 550,000 project trends as at April 2012. See<http: / /www. ohloh. net>.

8 Ohloh divides the number of lines of source code into "code", "comments", and "blanks". In this paper we use "code" to refer to the number of lines of source code. 
According to MacPherson et al. (2008) and Garcia-Garcia and Magdaleno (2010), OSS development costs and market value can be calculated by multiplying effort by wages. Based on these studies, we define the market value of OSS by formula (5), as follows.

$$
\text { OSS }_{t}=\left(\frac{E F F O R T_{t}}{12}\right) w_{t}
$$

In formula (5), man-year scale effort $\left(E F F O R T_{t} / 12\right)$ is obtained by dividing the manmonth effort by 12 (i.e. 12 months). Next, multiplying person-year effort by programmer's wages $w_{t}$ enables us to calculate the market value of OSS for every year as $\operatorname{OSS}_{t}{ }^{9}$. Because in economic theory, marginal cost and price are equal at market equilibrium point, effort for OSS development is equal to its market value ${ }^{10}$.

\section{$4 \quad$ Empirical Result}

\subsection{Labor Productivity}

Table1 shows the trend in labor productivity per Person-hour in Japan's information service industry for the period 2001 to 2009. Based on "Currently Survey of Selected Service Industries" published by Ministry of Economy, we divided this industry 8 enterprise groups in according to the number of its workers in Table1.

Regarding the labor productivity trend, three points can be deduced from Table 1. First, the level of labor productivity in an enterprise employing 500 or more workers is higher than that of other enterprises. This accounts for the discrepancies among enterprises within the same industry, as noted by Tanihana and Noda (2012). Second, Table 1 shows that the overall fluctuation of labor productivity is reduced, along with the scale of business expansion ${ }^{11}$. Moreover, after 2009 labor productivity level in this table reduces. It is caused by economic recession of those days.

From these features, it is obvious that an information service enterprise with over 500 workers, a so-called "big vendor", firmly maintains a high level of productivity. Again, it is possible to see the difference between big vendors and small vendors in terms of labor productivity in the Japanese information service industry.

9 There are two problems concerning programmer's wages. First, the wage level in Japan is lower than that of other countries. For example, programmers in Japan earned on average 3.5 million yen in 2000s. However, MacPherson et al.(2008) estimated that programmers earned \$7.5 thousand in 2008. Garcia-Garcia and Magdaleno (2010) estimate that programmers in Europe earned $€ 31$ thousand in 2006. Compared with these results, Japanese programmers' earn a low wage. Therefore, the possibility of an underestimation of market value of OSS cannot be denied. Second, OSS development is global, so using the Japanese average wage level is somewhat unfavorable. Ideally, we would use the time series data to reveal the developer's nationality and the proportion of their respective contributions. However, we were unable to obtain the data for such a calculation.

10 Then, we calculated the real OSS market value with the price index.

11 This figure shows that management becomes stable according to expansion of business scale. The gap of labor productivity in this figure results from vertical Japanese industrial (keiretsu-like) structure. See Tanihana and Noda (2012). 
Table 1. Labor Productivity per Per-hour in Japanese Information Service Industry

\begin{tabular}{|c|c|c|c|c|c|c|c|c|}
\hline & & & & & & & \multicolumn{2}{|c|}{$\begin{array}{r}\text { (Japanese yen } \\
\text { (exclude coefficient of } \\
\text { variation)) }\end{array}$} \\
\hline $\begin{array}{l}\text { Enterprise's } \\
\text { scale }\end{array}$ & $1-4$ & $5-9$ & $10-29$ & $30-49$ & $50-99$ & $100-299$ & $300-499$ & over500 \\
\hline 2001 & 1891 & 1530 & 1355 & 956 & 1029 & 1406 & 1095 & 2355 \\
\hline 2002 & 761 & 1557 & 959 & 1114 & 1032 & 1451 & 1190 & 2237 \\
\hline 2003 & 1927 & 1270 & 1134 & 1249 & 1098 & 1244 & 927 & 2315 \\
\hline 2004 & 1646 & 1493 & 1112 & 979 & 1065 & 1149 & 1136 & 2066 \\
\hline 2005 & 2708 & 2440 & 1729 & 1198 & 1320 & 1558 & 1528 & 2836 \\
\hline 2006 & 1495 & 2380 & 3795 & 2657 & 2899 & 2788 & 1699 & 4037 \\
\hline 2007 & 1519 & 4185 & 1590 & 1180 & 1450 & 1497 & 1773 & 4451 \\
\hline 2008 & 1413 & 1671 & 2101 & 1300 & 1412 & 1585 & 1065 & 3221 \\
\hline 2009 & 603 & 1137 & 1164 & 901 & 1178 & 1220 & 950 & 2817 \\
\hline Average & 1551 & 1962 & 1660 & 1282 & 1387 & 1544 & 1263 & 2926 \\
\hline $\begin{array}{l}\text { Coefficient } \\
\text { of Variation }\end{array}$ & 0.40 & 0.48 & 0.53 & 0.39 & 0.14 & 0.32 & 0.25 & 0.27 \\
\hline
\end{tabular}

\subsection{OSS Market Value}

Table 2 shows OSS market values estimated using formulas (4) and (5). This paper discusses the Linux kernel, MySQL, PostgreSQL, Apache HTTP Server, Perl, Ruby, Python, PHP, Ruby on Rails, and Open Office, which were objects of this study. Today, each of these 10 objectives are well known and widely used in the field of business. In table 2, the estimated period ranging from 2001 to 2010, except a small part.

Table 2. OSS Market Value

(Millions of Japanese

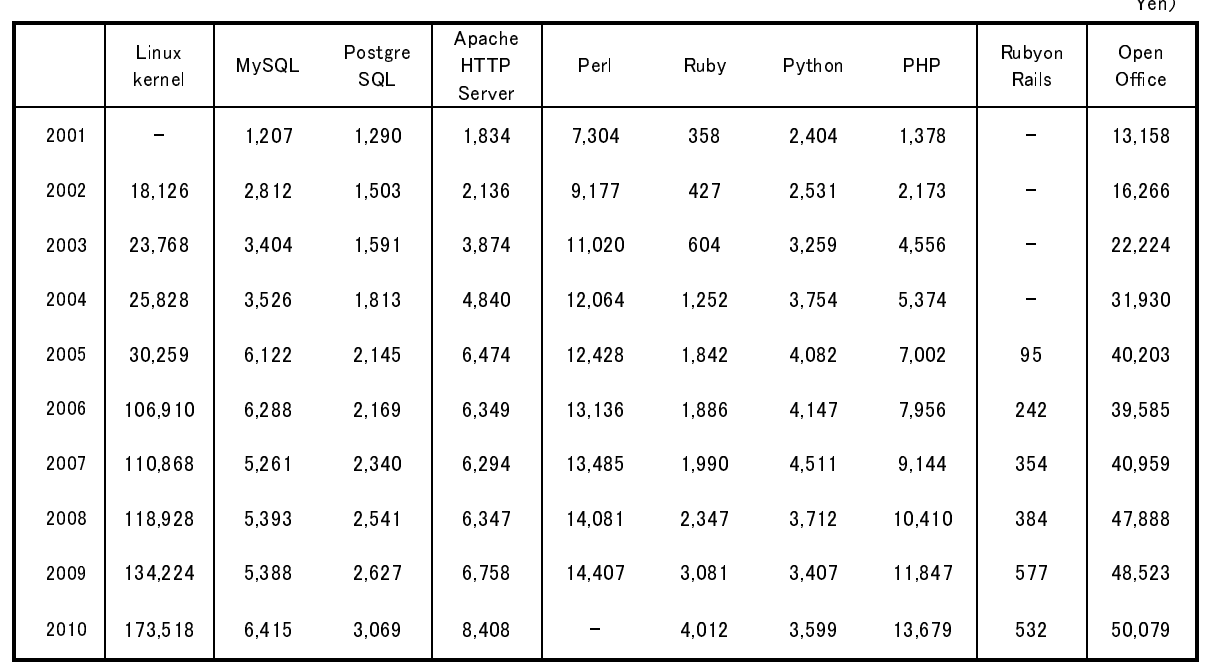


First, the Linux kernel typifies today's OSS movement. Table 2 shows that its market value was approximately 173.5 billion Yen in 2010. Table 2 clearly shows that no OSS has had the same market value as the Linux kernel during the period of this study. The reason for the high economic value of the Linux kernel is the high accumulation of its source code ${ }^{12}$.

Open Office is one of the office suite programs originally developed by Sun Microsystems and released as OSS in 2000. According to table 2, its market value was approximately 50 billion Yen in 2010. This figure ranks second to that of the Linux kernel.

On the other hand, Ruby on Rails is OSS that was still in the developmental stage. Because Ruby on Rails appeared in 2004, sometime after the other OSS, the accumulation level of its source code is low. This seems to explain its lower economic value.

\subsection{Contribution of OSS to Labor Productivity}

Table 3 shows the estimated contribution of OSS to the Japanese information service industry using a regression of formula (3). Our research objects are enterprises, which are categorized into 8 groups based on the "Current Survey of Selected Service Industries."

First, the estimated result shown in the second line of the upper section is the production structure of enterprises that do not use OSS. Because the elasticity of the ratio of the capital equipment is 0.292 , it is reasonable to conclude that the Japanese information service industry can enhance its productivity or ability to create added value through the enrichment of "inner" resources.

The estimated results of the Linux kernel are produced in the third line of the upper section, which shows that the contribution of the Linux kernel, when measured in terms of its elasticity, was 0.307 . We can conclude from this that the use of the Linux kernel has a positive economic effect on the Japanese information service industry.

We chose MySQL and PostgreSQL as the research objects in database server. Their results are shown in the fourth and fifth line of the upper section, respectively. The estimated elasticity of MySQL was 0.357 and for PostgreSQL it was 0.486. Based on these results, the Japanese information service industry could possibly enhance their labor productivity with these OSS.

The estimated elasticity of the Apache HTTP Server is indicated in the sixth line of the upper section, showing an estimated result of 0.278 . From this, it is plausible to conclude that the Apache HTTP Server has had a positive effect on the labor productivity of the information service industry in Japan.

As regards programming languages, we estimated the economic effect of four languages: Perl, Ruby, Python, and PHP. The elasticity estimates are shown in the seventh line of the upper section, as well as the second, third, third, and fourth lines of

12 The market value of the Linux kernel grew rapidly between 2005 and 2006. This was due to the rapid increase in code accumulation. 
Table 3. The Contribution of OSS to Productivity in Japanese Information Industry

\begin{tabular}{|c|c|c|c|c|c|c|}
\hline OSS type & With no OSS & Linuxkernel & MySQL & PostgreSQL & ApacheHTTPServer & Perl \\
\hline Covered Period & $2001-2009$ & $2002-2008$ & $2001-2009$ & $2001-2009$ & $2001-2009$ & $2001-2009$ \\
\hline$c$ & -4.860 & -13.058 & -12.821 & -14.941 & -11.000 & -16.807 \\
\hline $\ln (K / L)$ & $0.292(2.641) * *$ & $0.293(3.112) * * *$ & $0.287(2.672) * * *$ & $0.351(3.118) * * *$ & $0.305(2.801) * * *$ & $0.321(2.864) * * * *$ \\
\hline $\ln$ (OSS) & - & $0.307(5.271) * * * *$ & $0.357(3.212) * * *$ & $0.486(2.395) * *$ & $0.278(2.772) * * *$ & $0.521(2.011) * *$ \\
\hline $\begin{array}{l}\text { Covered } \\
\text { Period*The } \\
\text { Number of } \\
\text { Enterprise }\end{array}$ & 72 & 56 & 72 & 72 & 72 & 72 \\
\hline $\begin{array}{l}\text { Hausman-test } \\
\text { (p-value) }\end{array}$ & 0.830 & 0.852 & 0.995 & 0.886 & 0.968 & 0.947 \\
\hline $\begin{array}{l}\text { fixed effect or } \\
\text { random effect }\end{array}$ & random & random & random & random & random & random \\
\hline $\bar{R}^{t}$ & 0.086 & 0.347 & 0.203 & 0.148 & 0.172 & 0.126 \\
\hline OSS type & Ruby & Python & PHP & RubyonRails & OpenOffice & \\
\hline Covered Period & $2001-2009$ & $2001-2009$ & $2001-2009$ & 2005-2009 & $2001-2009$ & \\
\hline$C$ & -7.779 & -24.60 & -6.078 & -2.667 & -11.01 & \\
\hline $\ln (K / L)$ & $0.333(2.996) * * * *$ & $0.263(2.538) * *$ & $0.330(2.953) * * *$ & $0.495(3.007) * * *$ & $0.324(2.934) * * *$ & \\
\hline $\ln ($ OSS) & $0.150(2.423) * *$ & $0.890(4.215) * * *$ & $0.163(2.215) * *$ & $-0.048(0.491)$ & $0.261(2.477) * *$ & \\
\hline $\begin{array}{c}\text { Covered } \\
\text { Period*The } \\
\text { Number of } \\
\text { Enterprise } \\
\end{array}$ & 72 & 72 & 72 & 40 & 72 & \\
\hline $\begin{array}{c}\text { Hausman-test } \\
\text { (p-value) }\end{array}$ & 0.918 & 0.992 & 0.929 & 0.998 & 0.939 & \\
\hline $\begin{array}{l}\text { fixed effect or } \\
\text { random effect }\end{array}$ & random & random & random & random & random & \\
\hline$\vec{R}$ & 0.150 & 0.278 & 0.138 & 0.261 & 0.153 & \\
\hline
\end{tabular}

Note: t-values are in parentheses. $* *$ Significant at $5 \%$ level, ***Significant at $1 \%$ level.

the lower section. Although the estimated results are limited by the number of OSS selected for our study, we can still conclude that, generally speaking, OSS programming languages have had a positive effect on the Japanese information industry.

The estimated results for Ruby on Rails are shown in the fifth line of the lower section. Although its elasticity was -0.048 , which indicated a negative economic effect, its t-value was 0.491 . Therefore, Ruby on Rails seems not to have had any economic effect on the Japanese information service industry.

We estimated the economic effect of Open Office as an office suite OSS. The results are shown in the sixth line of the lower section. Judging from our results, we can conclude that Open Office has had a positive economic effect on Japan's information service industry.

\section{Conclusion}

The paper has discussed OSS from the viewpoint of a "open innovation". The free availability of OSS and the near zero cost in duplicating it are both aspects that are guaranteed by licenses, which leads us to view OSS as a kind of infrastructure or public good. 
Information service enterprises use OSS in the bid to strengthen their productivity and competitive advantage. Through the "bazaar" process, OSS is developed in a community that is organized independently from the enterprises contributing to such development.

Information service enterprises are able to create value by "connecting" OSS with their "internal" resources. Chesbrough defines this process as "open innovation" to denote a change in business model from a scale-intensive to a "connection"-intensive approach. It is therefore necessary to consider the effect of such a "connection" when analyzing the economic effect of OSS.

To conduct an analysis from an economic viewpoint, it is necessary to factor in the market value of OSS. For this purpose, we used COCOMO to calculate the market value. This calculation depended on effort. We found that the Linux kernel, and Open Office software have a high market value. In the case of Linux kernel, this is because their early appearance has facilitated the buildup of their source code, while the Open Office software's high value is attributable to the fact that it was originally developed as proprietary software, and has built up its source code since then. However, to calculate the market value of OSS, we had to rely on statistics for only Japan. Since the development of OSS is global, we concede that our exclusive reliance on Japanese statistics is not ideal. We had no other choice, though, because we were unable to obtain any data that provided a percentage breakdown of developers' respective nationalities and contributions. We would like to improve upon the method used in calculating the market value in a future study.

The calculation of the market value of OSS enabled us to estimate the contribution of OSS to labor productivity in the Japanese information service industry. We chose ten different kinds of OSS as our research object. The results of our analysis shows, broadly speaking, that although OSS has a positive economic effect on Japan's information service industry, each OSS has a variety of economic effects.

OSS has recently become an indispensable resource in the information service industry. This paper clarifies the relation between technical and economic productivity. In this connection, we can infer from our results that in order to create value and strengthen their competitiveness, information service enterprises will face subjects in style of OSS use. In other words, this will be essential in deciding which OSS will have a significant economic effect on the information service enterprise. However, to profit from the use of OSS, improvements to internal resources, such as talented developers, will also have to be made by such enterprises.

\section{References}

1. Ashauer, D.A.: Is Public Expenditure Productive? Journal of Monetary Economics 23, 177-200 (2001)

2. Boehm, B.: Software Engineering Economics. Englewood Cliff, New Jersey (1981)

3. Chesbrough, H.: Open Innovation. Harvard Business School, Boston (2003)

4. Coase, R.H.: The Nature of the Firm. Economica, 386-405 (1937)

5. Ford, R., Pierre, P.: Infrastructure and Private-sector Productivity. OECD Economic Studies 17, 63-89 (1991) 
6. Fukuyasu, N.: Economic Model about Open Source. The Linux Foundation (2011), http: / /www.ospn.jp/osc2011-spring/pdf / osc2011spring_tne_linux_foundation.pdf

7. Garcia-Garcia, J., Magdaleno, M.I.A.: Commons-based Innovation The Linux Kernel Case (2010), http: / /iri.jrc.ec.europa.eu/ concord-2010/posters / Garcia-GarcGa.ppt

8. Ghosh, R.A.: Cooking-pot Markets: An Economic Model for the Trade in Free Goods and Services on the Internet. First Monday 3(3) (1998), http: / / firstmonday . org / htbin/cgiwrap/bin/ojs/index.php/fm/issue/view/90

9. Glott, R., Haalamd, K.: Open Source and Regional Promotion. This document is prepared for the lecture in Shimane University, July 17 (2009)

10. Kokuryo, J.: Open Network Management. Nikkei Inc., Tokyo (1995)

11. Kunai, T.: Let's go with Linux. LINUX.COM (2010), https://jp.linux.com/whats-new/column/kunai

12. The Linux Foundation, Linux Kernel Development (2008), http: / /www. linuxfoudation.org

13. MacPherson, A., Proffitt, B., Hale-Evans, R.: Estimating the Total Development Cost of a Linux Distribution. The Linux Funndation (2008), http://www. linuxfoundation.org/sites/main/files/ publicpublica/estimatinglinux.html

14. Miyazawa, K.: Distribution Structure in Highly Informative Society: Development of Network-type System. Toyo Keizai Inc., Tokyo (1986a)

15. Miyazawa, K.: Industrialized Society: Pursuit of the Economy of Connection through synergy between knowledge and technology. Nihon Keizai Shinbun, Tokyo (1986b)

16. Miyazawa, K.: Economics of System and Information. Yuhikaku Inc., Tokyo (1988)

17. Raymond, E.: Cathedral and Bazarr (1998), http: / /www . catb.org / resr/writings/cathedral-Bazarr/cathedral-Bazarr/

18. Suematsu, C.: Open Source and The IT Strategy in Next Generation. Nikkei Inc. (2004)

19. Tanihana, K., Noda, T.: Open Source Software and Productivity of Information Service Industries. In: JSIS\&JASI Proceeding, The Japan Association Social Informatics, Tokyo, pp. 357-362 (2011)

20. Tanihana, K., Noda, T.: Study on Production Structure of Information Service Industry in Japan. Journal of Economics Memoirs of the Faculty of Law and Literature, 93-120 (2012)

21. Wheeler, D.A.: SLOCCount User's Guide (2004), http://www.dweeler.com/sloccount/sloccount.html 